\title{
МОДЕРНИЗАЦИЯ ТЕХНОЛОГИИ ШЕЛУШЕНИЯ ЗЕРНА ОВСА
}

\section{D.S. Bezyazykov, V.N. Nevzorov, I.V. Matskevich}

\section{THE MODERNIZATION OF TECHNOLOGY OF OATS GRAIN FLAKING}

Безъязыков Денис Сергеевич - ассист. каф. технологии, оборудования бродильных и пищевых производств Красноярского государственного аграрного университета, г. Красноярск.

E-mail: Haast13@mail.ru

Невзоров Виктор Николаевич - д-р с.-х. наук, проф., зав. каф. технологии, оборудования бродильных и пищевых производств Красноярского государственного аграрного университета, г. Красноярск. E-mail: nevzorov1945@mail.ru Мацкевич Игорь Викторович - канд. техн. наук, доц. каф. технологии, оборудования бродильных и пищевых производств Красноярского государственного аграрного университета, г. Красноярск. E-mail: imatskevichv@mail.ru

Технический анализ научно-технической литературы по исследованию шелушения зерна овса показал, что для выполнения данной операции не требуется сильного воздействия рабочих органов на зерно, так как цветковые пленки не срастаются с ядром. Основным недостатком существующих технологий шелушения зерна овса является длительность процесса вследствие использования в оборудовании абразивных покрытий и низкий выход готового продукта, при этом наиболее ценные составные части зерновки, включая пищевые волокна и зародыш, удаляются в отруби. Разработана модернизированная технология шелушения овса, состоящая из последовательных операций, включающих гидротермическую обработку с непрерывным перемешиванием зерна овса и подачей пара, подсушку зерна с использованием горячего воздуха, шелушение зерна овса щеточно-вихревым способом и вибрационное разделение зернового вороха на цельное и дробленое зерно и отделение шелухи. Для выполнения работ по данной технологии была разработана машина для шелушения зерна пленчатых культур, которая является универсальной и совмещает по-
Bezyazykov Denis Sergeevich - Asst, Chair of Technology, Equipment of Fermentative and Food Productions, Krasnoyarsk State Agrarian University, Krasnoyarsk.

E-mail: Haast13@mail.ru

Nevzorov Victor Nikolaevich - Dr. Agr. Sci., Prof., Head, Chair of Technology, Equipment of Fermentative and Food Productions, Krasnoyarsk State Agrarian University, Krasnoyarsk.

E-mail: nevzorov1945@mail.ru

Matskevich Igor Victorovich - Cand. Techn. Sci., Assoc. Prof., Chair of Technology, Equipment of Fermentative and Food Productions, Krasnoyarsk State Agrarian University, Krasnoyarsk.

E-mail: imatskevichv@mail.ru

следовательное выполнение рабочих операций в одном технологическом потоке, включая пропаривание, сушку и шелушение зерна овса с помощью щеточно-вихревого механизма, установленного в корпусе шелушителя, новизна конструкции которой выполнена на уровне изобретения, что подтверждается патентом Российской Федерации № 2709767 «Машина для шелушения зерна пленчатых культур», максимальное значение величины выхода цельного зерна возможно при длительности пропаривания 40 минут, что закладывается в технологические параметры технических условий для шелушения зерна овса.

Ключевые слова: зерно овса, технология, патентные исследования, машина, шелушение зерна, продукты шелушения.

Technical analysis of scientific and technical literature studying of oat grain peeling showed that this operation did not require strong impact of working bodies on the grain, since flower films did not fuse with the core. The main drawback of existing oat grain peeling technologies was the length of the process due to using abrasive coatings in the equipment and low yield of finished product, while 
the most valuable components of grain, including dietary fibers and germ, were removed in bran. Upgraded oat peeling technology was developed, consisting of sequential operations including hydrothermal treatment with continuous mixing of oat grain and steam supply, grain drying using hot air, oat grain flaking by brush-vortex method, and vibration separation of the grain pile into whole and crushed grains and husk separation. To perform the work on this technology, the machine for peeling grain of film crops was developed, which was universal and combined sequential execution of working operations in one technological flow including steaming, drying and peeling of oat grain using a brush-vortex mechanism installed in the casing of the husker, the novelty of the design of made at the level of the invention, which is confirmed by the patent of the Russian Federation No. 2709767 "Machine for peeling grain of film crops", the maximum value of the yield of whole grain was possible when steaming time was 40 minutes, which was laid down in technological parameters of technical conditions for oat grain peeling.

Keywords: oat grain, technology, patent researches, machine, grain peeling, peeling products.

Введение. В природно-климатических условиях Красноярского края овес является одной из основных зерновых культур. Зерно овса неприхотливо к погодным условиям и даже при температуре $-5^{\circ} \mathrm{C}$ уже начинает прорастать, что дает определенные плюсы при посеве данной культуры. С полей Красноярского края за 2019 год собранно 440,5 тыс. тонн зерна овса при средней урожайности 24,8 центнера с гектара [1]. Зерно овса широко используется при изготовлении пищевых продуктов, таких как овсяная недробленая крупа, целая плющеная крупа, и большого ассортимента овсяных хлопьев [2, 3]. По существующим технологиям пищевые продукты из зерна овса получают путем пофрракционного шелушения зерна с разделением продуктов шелушения в рассеве, воздушном сепараторе и на пади-машине с последующим шлифованием, а готовую крупу также контролируют в рассеве, воздушном и магнитном сепараторах. Данная технология, по которой работают большинство крупяных и мукомольных производств России, требует использования большого количества энергоемких машин для выполнения рабочих операций, что приводит к длительности технологического процесса и повышает себестоимость продукции [4].

Цель исследования. Модернизация технологии и разработка оборудования для шелушения зерна овса.

Задачи исследования: изучить технологию шелушения зерна овса и разработать технологическую схему; провести патентные исследования для выбора аналога и прототипа, используемых при разработке технического решения машины для шелушения зерна; провести опытно-лабораторные исследования применения щеточно-вихревого механизма для шелушения зерна овса, прошеднего гидротермическую обработку; выполнить математическую обработку полученного экспериментального материала для обоснования технологических параметров процесса шелушения зерна овса.

Объекты и методы исследования. Объектом исследования является процесс шелушения пропаренного зерна овса с использованием щеточно-вихревого технологического оборудования для шелушения зерна овса, с использованием методов сравнительного анализа, опытноэкспериментальных испытаний, математического моделирования и проведение патентных исследований по международным и российским информационным базам, содержание и порядок проведения которых определены ГОСТ P 15.011-96 «Система разработки и постановки продукции на производство».

Результаты и их обсуждение. Разработанная новая технология шелушения овса предусматривает на первом этапе уплотнение зерна овса с помощью использования конусного подающего шнекового устройства перед гидротермической обработкой с конусным специальным шнеком для свободного прохода пара и перемешивателем для удаления застойных зон [5]. В дальнейшем сушка пропаренного зерна овса происходит при его попадании в камеру шелушения за счет подачи теплого воздуха вовнутрь корпуса по внутренним полым стойкам до влажности 10-14 \%, при этом происходит процесс шелушения щеточно-вихревым механизмом в камере шелушителя и подача шелушенного продукта на вибростол для разделения шелушеной массы на цельное, дробленое зерно и удаление воздушным потоком шелухи. Модернизированная технологическая схема представлена на рисунке 1. 


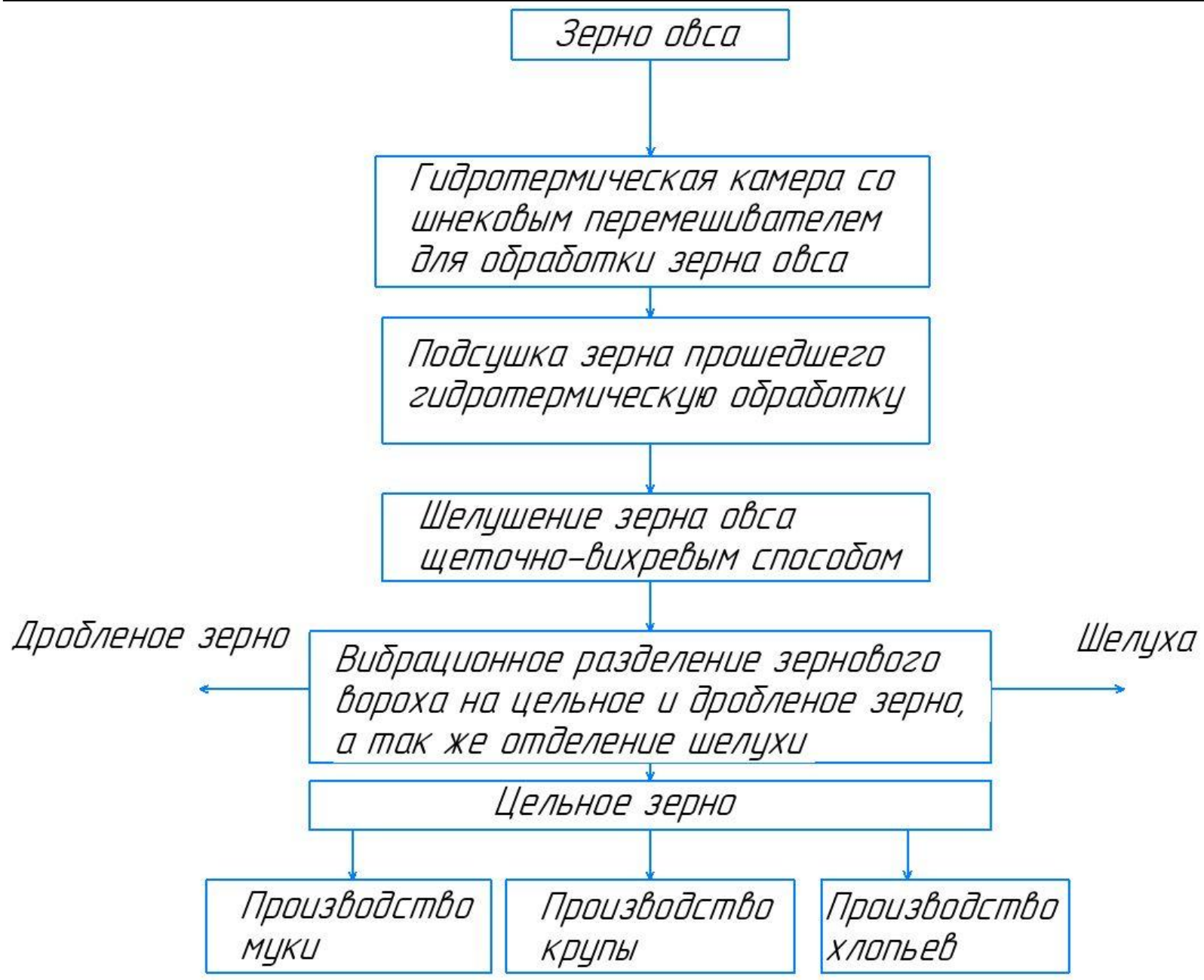

Puc. 1. Модернизированная технология шелушения зерна овса

С целью практической реализации применения новой технологии шелушения зерна овса была разработана машина для шелушения зерна пленчатых культур, обеспечивающая увеличение выхода цельного зерна при шелушении и удалении семенной оболочки, не подвергая воздействию алейроновый слой зерна. На разработанное техническое предложение была подана нормативно-техническая документация и получен патент Российской Федерации № 2709767 «Машина для шелушения зерна пленчатых культур» [6].

Кинематическая схема машины для шелушения зерна пленчатых культур приведена на рисунке 2, на рисунке 3 представлен разрез машины для шелушения зерна в месте соединения корпуса шелушителя с корпусом очистителя. 

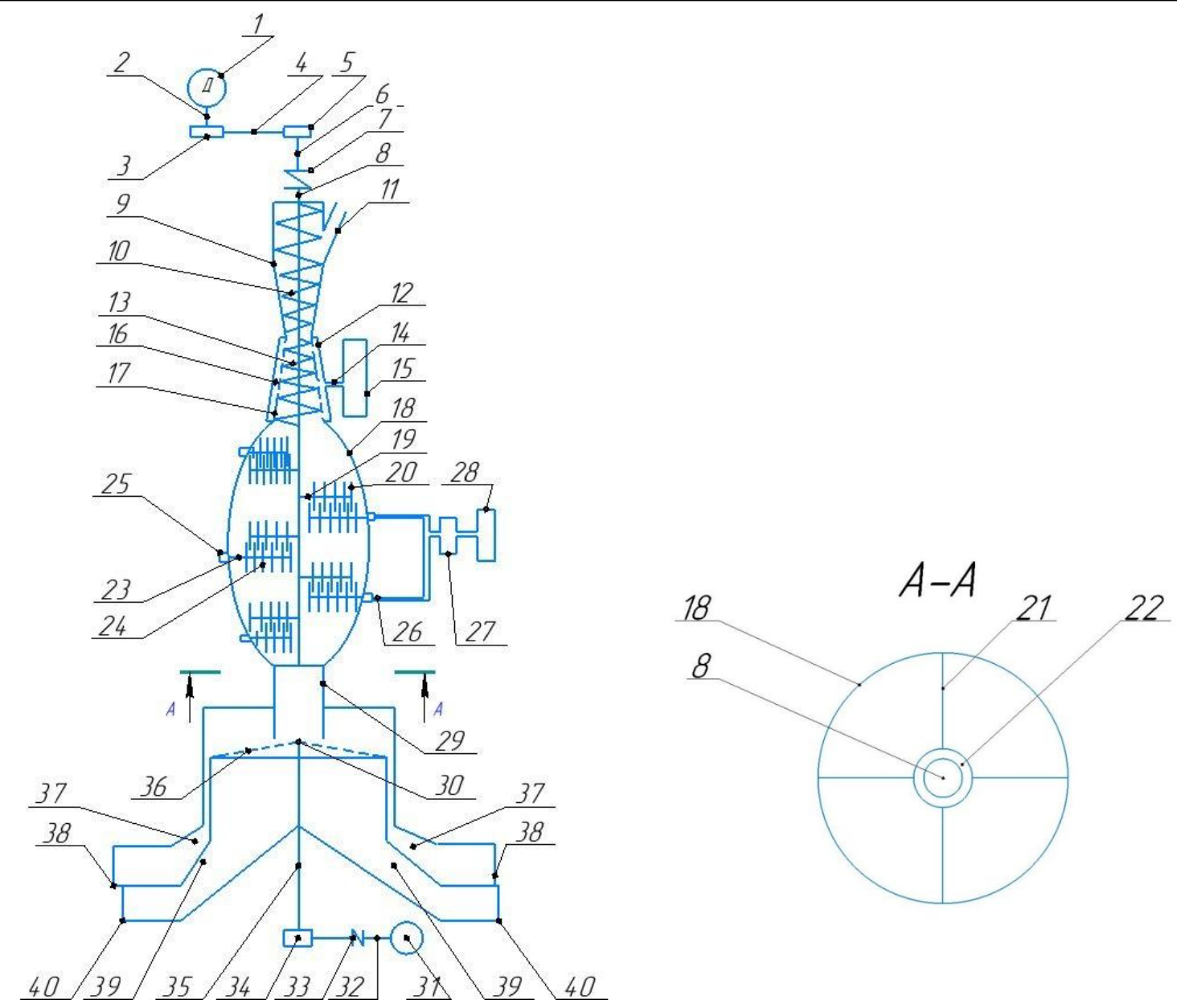

Puс. 2. Схема машины для шелушения зерна пленчатых культур

Машина для шелушения зерна пленчатых культур работает следующим образом. Включаются электродвигатели 1 и 31. Зерно попадает в корпус 9 через загрузочное отверстие 11 и продвигается при помощи шнековой навивки 10, установленной на приводном валу 8. Шнековая навивка 10 приводится в движение при помощи электродвигателя 1 , передающего крутящий момент на вал 2, через ведущую шестерню 3 и ременную передачу 4 ведомой шестерне 5 на вал 6 через муфту 7, на приводной вал 8. Приводной вал 8 закреплен на четырехлучевой опоре 21 в подшипниковом узле 22 в овальном корпусе шелушителя 18.

При продвижении по шнековой навивке 10 зерно попадает в конусный корпус пропаривателя 12, в котором на приводном валу 8 установлен шнек 13 для продвижения зерна, расширяющийся в конусном корпусе пропаривателя 12. Зерно пропаривается за счет парогенератора 15, подающего пар по трубкам 14 в распре- делительную рубашку 16, и через отверстия 17 попадает в конусный корпус пропаривателя 12.

Пропаренное зерно из конусного корпуса пропаривателя 12 при помощи шнека 13 попадает в овальный корпус шелушителя 18, где под воздействием щеток 20, закрепленных на стойках 19, установленных на приводном валу 8, и щеток 24, установленных на полых стойках 23 , происходит отшелушивание зерна, также при отшелушивании зерно подсушивается за счет подачи воздуха, создаваемого компрессором 28 через калорифер 27 по воздухподающим патрубкам 26, через обратный клапан 25 попадает внутрь полой стойки 23.

Очищенное зерно и зерновой ворох продвигается в нижнюю часть овального корпуса шелушителя 18, по патрубку 29 попадает на вибростол 30, приводимый в движение с помощью электродвигателя 31, через вал 32, муфту 33 через вибропривод 34 передает вибрацию на вал 35. Зерно, перемещаясь по вибростолу 30 , 
продвигается к отверстиям 36 и удаляется по патрубкам 39 в приемный бункер 40, а шелуха под действием вибростола попадает в патрубки 37 и удаляется в приемный бункер 38.

Для обоснования оптимальных параметров при работе машины для шелушения зерна овса были проведены лабораторные экспериментальные исследования влияния гидротермической обработки на выход цельного зерна при шелушении.

Экспериментальные исследования показали, что наибольший выход цельного зерна овса достигается при гидротермической обработке с продолжительностью 35-40 минут, при которой достигается выход цельного зерна, равный 85$90 \%$ от общей массы исходной навески, выход дробленого зерна, равный 4-6 \% от общей массы, и выход шелухи 4-11\% от общей массы.

Для построения теоретического графика математической модели влияния продолжительности гидротермической обработки на выход массы цельного зерна были обработаны экспериментальные данные с использованием программ MS Excel, Curveexpert, и результаты обработки представлены в виде графика на рисунке 3.

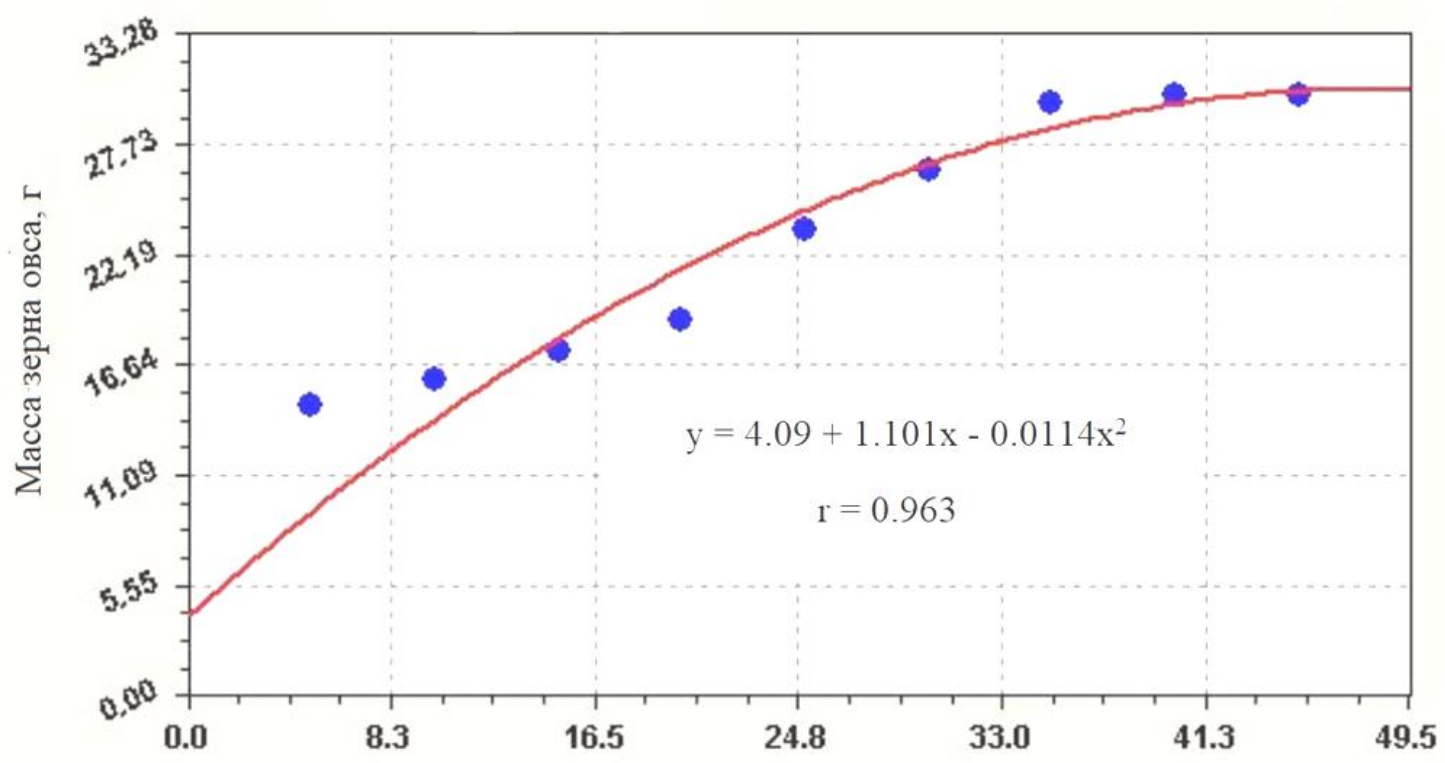

Продолжительность гидротермической обработки, мин

Puc. 3. График влияния гидротермической обработки на выход массы цельного зерна овса

Адекватность полученной математической модели влияния продолжительности гидротермической обработки на выход массы цельного зерна овса проверяли по фрактическому критерию хи-квадрат $\left(X^{2}\right)$ с табличным значением $\left(X^{2} \phi\right.$ - 2,907), при доверительной вероятности 0.95 табличное значение $\left(x^{2}{ }_{s t}-6,0\right)$, поскольку $X^{2}{ }_{\phi}<X^{2}{ }_{s t}$ нулевую гипотезу отвергуть нельзя. На этом основании следует заключить, что во влиянии продолжительности гидротермической обработки на выход массы цельного зерна овса хорошо согласуются экспериментальные и теоретические параметры. Значимость коэффрициентов уравнений проверялась по коэффрициенту корреляции, который равен: $r=0,962$. По полученным данным было построено уравнение криво- линейной регрессии вида: $y=a+b x+c x^{2}$, где $a=$ $4,09, b=1,101, c=-0,0114$. Анализ графической зависимости (рис. 3), а также расчеты в программе Curveexpert показывают, что максимальное значение величины выхода цельного зерна возможно при длительности пропаривания 40 минут, что закладывается в технологические параметры технических условий для шелушения зерна овса.

\section{Выводы}

1. Изучены современные технологии и оборудование для шелушения зерна овса, которые используют гидротермическую обработку и абразивные механизмы шелушения. Недостатком 
используемых технологий и оборудования является большой по массе выход дробленого зерна и необоснованно высокий выход мелкодисперсной мучки.

2. Проведены патентные исследования по российской и мировой базам данных, которые позволили определить аналог и прототип изобретений, используемых при разработке нового оборудования, новизна конструкции которого защищена патентом РФ № 2709767 «Машина для шелушения зерна пленчатых культур».

3. Проведены опытно-лабораторные исследования процесса шелушения зерна овса с использованием щеточно-вихревого механизма и определены качественные показатели выхода цельного зерна овса, прошедшего гидротермическую обработку.

4. Выполнена математическая обработка полученного экспериментального материала и определена форма криволинейной связи, построена математическая модель влияния продолжительности гидротермической обработки на выход массы цельного зерна овса и определена теснота связи и параметры уравнения криволинейной регрессии.

\section{Литература}

1. Экспериментально-аналитический центр агробизнеса: овес: площади, сборы и урожайность в 2001-2019 гг. URL: https://abcentre.ru/news/oves-ploschadi-sbory-iurozhaynost-v-2001-2019-gg.

2. Игорянова Н.А., Мелешкина Е.П., Коломиец С.Н. Новые свойства овса с позиции здорового питания // Научно-инновационные аспекты хранения и переработки зерна. М.: Типография Россельхозакадемии, 2014. C. 103-105.

3. Новое оборудование для переработки зерновых культур в пищевые продукты / B.A. Самойлов, А.И. Ярум, В.Н. Невзоров [и др.]; Краснояр. гос. аграр. ун-т. Красноярск, 2017. 198 c.

4. Технология и оборудование биотехнологической переработки зерна злаковых куль- тур / В.Н. Невзоров, С.В. Хижняк, М.А. Янова [и др.]. Красноярск, 2019. 148 с.

5. Безъязыков Д.С., Невзоров В.Н. Разработка технологии и оборудования для пропаривания овса // Проблемы современной аграрной науки: мат-лы междунар. науч. конф. Краснояр. гос. аграр. ун-та. Красноярск, 2018. С. 186-189.

6. Патент Российской Федерации № 2709767 В02В 5/02, В02В 3/00 19.12.2019. Машина для шелушения зерна пленчатых культур / Невзоров В.Н., Мацкевич И.В., Безъязыков Д.С. Бюл № 35.

\section{Literatura}

1. Jeksperimental'no-analiticheskij centr agrobiznesa: oves: ploshhadi, sbory i urozhajnost' v 2001-2019 gg. URL: https://abcentre.ru/news/oves-ploschadi-sbory-iurozhaynost-v-2001-2019-gg.

2. Igorjanova N.A., Meleshkina E.P., Kolomiec S.N. Novye svojstva ovsa s pozicii zdorovogo pitanija // Nauchno-innovacionnye aspekty hranenija i pererabotki zerna. M.: Tipografija Rossel'hozakademii, 2014. S. 103-105.

3. Novoe oborudovanie dlja pererabotki zernovyh kul'tur v pishhevye produkty / V.A. Samojlov, A.I. Jarum, V.N. Nevzorov [i dr.]; Krasnojar. gos. agrar. un-t. Krasnojarsk, 2017. 198 s.

4. Tehnologija i oborudovanie biotehnologicheskoj pererabotki zerna zlakovyh kul'tur / V.N. Nevzorov, S.V. Hizhnjak, M.A. Janova [i dr.]. Krasnojarsk, 2019. $148 \mathrm{~s}$.

5. Bez'jazykov D.S., Nevzorov V.N. Razrabotka tehnologii i oborudovanija dlja proparivanija ovsa // Problemy sovremennoj agrarnoj nauki: mat-ly mezhdunar. nauch. konf. Krasnojar. gos. agrar. un-ta. Krasnojarsk, 2018. S. 186-189

6. Patent Rossijskoj Federacii № 2709767 V02V 5/02, V02V 3/00 19.12.2019. Mashina dlja shelushenija zerna plenchatyh kul'tur. I Nevzorov V.N., Mackevich I.V., Bez'jazykov D.S. Bjul № 35. 